\title{
Reflexos das Mudanças na Concorrência do Setor da Aviação Comercial Brasileiro: Um Estudo no Âmbito da Desregulamentação Governamental e da Entrada da Companhia Gol
}

\begin{abstract}
Genossi Rauch Miotto
Mestrado em Ciências Contábeis pela Universidade do Vale do Rio dos Sinos UNISINOS

Professora da Universidade do Vale do Rio dos Sinos UNISINOS

Av. Unisinos, 950. Cristo Rei. São Leopoldo/RS. CEP: 93022-000 E-mail: ge.miotto@terra.com.br

Marcos Antonio de Souza Doutorado em Controladoria e Contabilidade - Faculdade de Economia, Administração e Contabilidade da Universidade de São Paulo - FEA/USP Professor da Universidade do Vale do Rio dos Sinos - UNISINOS Av. Unisinos, 950. Cristo Rei. São Leopoldo/RS. CEP: 93022-000 E-mail:marcosas@unisinos.br

Carlos Alberto Diehl Doutorado em Engenharia de Produção pela Universidade Federal de Santa Catarina - UFSC Professor da Universidade do Vale do Rio dos Sinos - UNISINOS Av. Unisinos, 950. Cristo Rei. São Leopoldo/RS. CEP: 93022-000 E-mail: cd@unisinos.br
\end{abstract}

\section{RESUMO}

O objetivo do presente artigo é analisar os reflexos sobre o desempenho das empresas aeroviárias pelas recentes mudanças estruturais no setor de aviação comercial brasileiro em âmbito doméstico. Essas mudanças estruturais deram-se em função de três acontecimentos específicos: a desregulamentação governamental do setor com a queda de uma barreira a novos entrantes; a atuação da companhia Gol como nova entrante e o acirramento da concorrência no setor. A análise é feita por meio de seis variáveis principais: participação de mercado, tarifa média, aproveitamento de aeronaves, gasto médio por passageiro, margem operacional e quantidade de passageiros transportados. É um estudo descritivo, realizado com a utilização de dados quantitativos coletados por meio de pesquisa documental nos anuários da ANAC para o período de 1997 a 2006. Os principais resultados revelam que a nova entrante Gol provocou mudança significativa na estrutura estratégica e operacional do setor e das principais concorrentes. Em todas as variáveis analisadas o desempenho da Gol superou suas concorrentes. Constatou-se que a empresa mais preparada estrategicamente para responder à nova ameaça foi a Tam, que mantém a liderança no setor. Outras empresas como a Vasp e a Varig se mostraram incapazes de sobreviver à livre concorrência de mercado.

Palavras-Chave: Aviação Comercial. Desregulamentação. Novos Entrantes. Cia Gol 
de Aviação.

\title{
Consequences of the Changes in Competition of the Brazilian Sector of Commercial Aviation: A Study in the Scope of the Governmental Deregulation and the Entrance of the Company Goal
}

\begin{abstract}
This article aims is to analyze the consequences on the performance of the aircraft companies from the recent structural changes in the Brazilian sector of commercial aviation in domestic scope. These structural changes had been given in function of three specific events: the governmental deregulation of the sector as fall of barrier to new entrants; the performance of the Goal company as new entrant ones in the competition of the sector. The analysis is made by means of six main variables: (1) participation of market; (2) tariffs average; (3) exploitation of aircraft; (4) average expense for passenger; (5) operational edge; (6) amount of carried passengers. The adopted research methodology comprised a descriptive study using a quantitative approach and documentary analysis based on yearbooks of the ANAC for the period from 1997 to 2006. The main research results showed that new entrant Goal provoked significant change in the strategical and operational structure of the sector and the main competitors. In all variables analyzed the performance of the Goal surpassed its competitors. Other evidence is that Tam company is more strategically prepared to answer to the new threat and keeps the leadership in the sector. Other companies like Vasp and Varig, had revealed incapable to survive to the free competition of market.
\end{abstract}

Palavras-Chave: Commercial Aircraft. Deregulation. New Entrants. Gol Aircraft Company.

\section{INTRODUÇÃO}

$\mathrm{Na}$ atualidade, a maioria dos trabalhos publicados em revistas especializadas tem ressaltado a necessidade de o gestor observar os ambientes interno e externo no qual as empresas estão inseridas, para buscar identificar e desenvolver estratégias competitivas com o objetivo de assegurar a continuidade dos negócios.

A globalização e a consequente intensificação no nível de concorrência, que caracterizam a realidade atual do ambiente operacional das empresas, tem sido o principal argumento apresentado quando se discute o desenvolvimento e adoção de estratégicas competitivas. O trabalho de Porter (1989) tem sido uma 
das principais referências a este respeito.

No Brasil, as principais modificações no ambiente operacional externo das empresas referem-se às transformações na economia observadas nas décadas de 1980 e 1990. Tais transformações têm provocado uma ruptura de paradigmas em relação à administração dos negócios que até então estava focada nos preços, consequência do protecionismo de uma economia desajustada. Estes acontecimentos também impactaram setores considerados estratégicos e de segurança governamental, e por isso sob forte regulamentação oficial. É o caso da flexibilização na proteção dada ao setor de aviação comercial (Monteiro, 2000).

Jesus (2005) aborda que a desregulamentação ocorrida em 1978 nos Estados Unidos deu início ao processo de desregulamentação e profundas mudanças no setor de aviação comercial em âmbito mundial. Tal movimento provocou, a partir da década de 1980, a abertura da concorrência no setor aéreo brasileiro, gerando maior oferta de serviços por novas empresas e uma mudança dos conceitos sobre transporte aéreo e da sua gestão.

É neste contexto que o artigo é desenvolvido, com o objetivo de descrever e analisar as mudanças ocorridas no ambiente concorrencial neste setor. Mais especificamente, procura-se evidenciar os reflexos que a transição de um setor protegido por barreiras governamentais para um ambiente de concorrência de mercado, provoca no posicionamento estratégico e desempenho das empresas. Entende-se que com esse objetivo o estudo contribui para evidenciar aos gestores as implicações ambientais sobre o processo decisório das organizações. De fato, a passagem de uma atividade protegida para uma exposição às forças de mercado enseja mudanças de posturas e atitudes. A apresentação dos efeitos no desempenho e resultado das empresas, como apresentado neste estudo, é uma das alternativas para tal evidenciação.

Ressalta-se que o grande apelo que o tema vem recebendo ultimamente pela mídia tem se restringido às questões infra-estruturais físicas do sistema e ao desconforto que tem provocado aos usuários. Questões relacionadas à gestão estratégica das empresas, no âmbito de um mercado concorrencial da forma 
como tratado neste estudo, não tem sido abordado pela mídia.

\section{REFERENCIAL TEÓRICO}

\subsection{O Ambiente Competitivo}

O ambiente externo, às empresas, vem sofrendo ao longo do tempo um constante processo de mudanças. A compreensão das mudanças, ocorridas ou a ocorrer, assim como o grau de interação da empresa com esse ambiente é determinante para que ela alcance o sucesso desejado. Dentre outros fatores que podem impactar significativamente o ambiente externo podem ser citados: a intensidade da concorrência entre as empresas; as exigências dos consumidores; as incertezas políticas e econômicas; e os avanços tecnológicos.

Em função dos movimentos de maior liberalização de mercados no contexto mundial, a intensidade da concorrência entre as empresas atuantes num mesmo setor tem ganho particular destaque. Além disso, a capacidade das empresas em superar as complexidades decorrentes e desenvolver alternativas estratégicas efetivas tem sido reconhecida como uma vantagem competitiva. A maior disputa na conquista e manutenção de clientes trouxe como consequência, dentre outros fatores, o aumento das exigências do mercado consumidor. A agilidade em satisfazer o cliente tem se tornado sinônimo de excelência empresarial, e exigido das empresas constante inovação nos produtos, nos serviços e também no processo de gestão (Nakagawa, 2000).

Tais mudanças mercadológicas exigem, também, que as empresas se antecipem e tenham uma visão de longo prazo cada vez mais eficaz. Não basta, contudo, apenas a interação da empresa com o ambiente externo e as boas estratégias de atuação no mercado, é fundamental a eficiência nos processos internos. Neste sentido, processos internos devem ser interpretados como a forma de atender as expectativas do cliente. No entendimento de Hammer (2001) as organizações orientadas por processos são aquelas que deixam os clientes mais satisfeitos e, consequentemente, conquistam mais mercados e lucros.

Mosimann e Fisch (1999) enfatizam que as empresas exercem atividades 
econômicas como: o consumo de recursos; a produção de bens e serviços; e a venda. As atividades de produção estão ligadas ao ambiente interno da empresa, e devem ser as mais eficientes possíveis. Porém, as atividades de venda sofrem impactos das variáveis externas, relacionadas, principalmente, ao mercado consumidor e aos concorrentes.

O ciclo de atividades econômicas citado por Mosimann e Fisch é interdependente, e o planejamento empresarial não poderá tratá-lo de forma individualizada. A estratégia vencedora passa pelo reconhecimento de que a empresa deve produzir mais eficientemente, e melhor do que os concorrentes aqueles produtos que o mercado almeja.

Otley (1994), na mesma linha de entendimento de Hammer (2001), já argumentava que em um ambiente competitivo as organizações obtêm resultados positivos e sobrevivem por meio da adaptação aos padrões mercadológicos; seu sucesso decorre das inovações corporativas. Isso requer não somente um foco externo na competitividade e na inovação de produtos e serviços, mas, também, um foco interno no planejamento e no controle das atividades e processos internos.

O planejamento deve partir de um diagnóstico das expectativas e das necessidades do mercado e, a partir disso, a empresa deverá planejar a estrutura necessária para o atendimento dessa demanda com a maior eficiência possível. A eficiência empresarial é um fator determinante no atual ambiente competitivo, pois os clientes não mais se dispõem a pagar pelas ineficiências da empresa. Caso elas existem, será muito provável que a empresa venha a sofrer as consequências, através da perda de participação de mercado e/ou redução da lucratividade (Hansen e Mowen, 2001).

A compreensão das inter-relações e complexidades que envolvem 0 ambiente de operações das empresas foi favorecida com os estudos desenvolvidos por Porter (1986), o qual defende que para compreender o ambiente competitivo existente num mercado, é necessária uma metodologia especifica de análise. Foi com esse objetivo que ele propôs a análise das cinco forças competitivas, conteúdo da próxima seção. 


\subsection{Posicionamento Estratégico e Vantagem Competitiva}

Posicionar-se estrategicamente tornou-se uma necessidade constante para as empresas, dadas as complexidades e os desafios do ambiente competitivo. Autores como Mintzberg, Ahlstrand e Lampel, (2000) defendem técnicas de análise e posicionamento, desde um planejamento estratégico formalmente estruturado, até modelos não estruturados de formação de estratégias.

Porter (1989, p. 2) advoga que o primeiro passo antes de elaborar a estratégia competitiva global é conhecer o setor onde a empresa está atuando ou pretende atuar, e acrescenta que "a estratégia competitiva não só responde ao meio ambiente, mas também tenta modelar este meio ambiente em favor de uma empresa".

Ainda de acordo com Porter (1986), o conhecimento da concorrência em um mercado pode ser resumido em cinco forças competitivas (Figura 1), as quais devem ser estudadas, a fim de se estabelecer uma estratégia competitiva. São elas: (1) rivalidade entre os concorrentes existentes; (2) entrada de novos concorrentes; (3) ameaça de substitutos; (4) poder de negociação dos compradores; (5) poder de negociação dos fornecedores. As principais características de cada um dos elementos, que no conjunto compõem as forças e ameaças da competição, são apresentadas na sequência. 
Reflexos das Mudanças na Concorrência do Setor da Aviação Comercial Brasileiro: Um Estudo no Âmbito da Desregulamentação Governamental e da Entrada da Companhia Gol Genossi Rauch Miotto, Marcos Antonio de Souza, Carlos Alberto Diehl

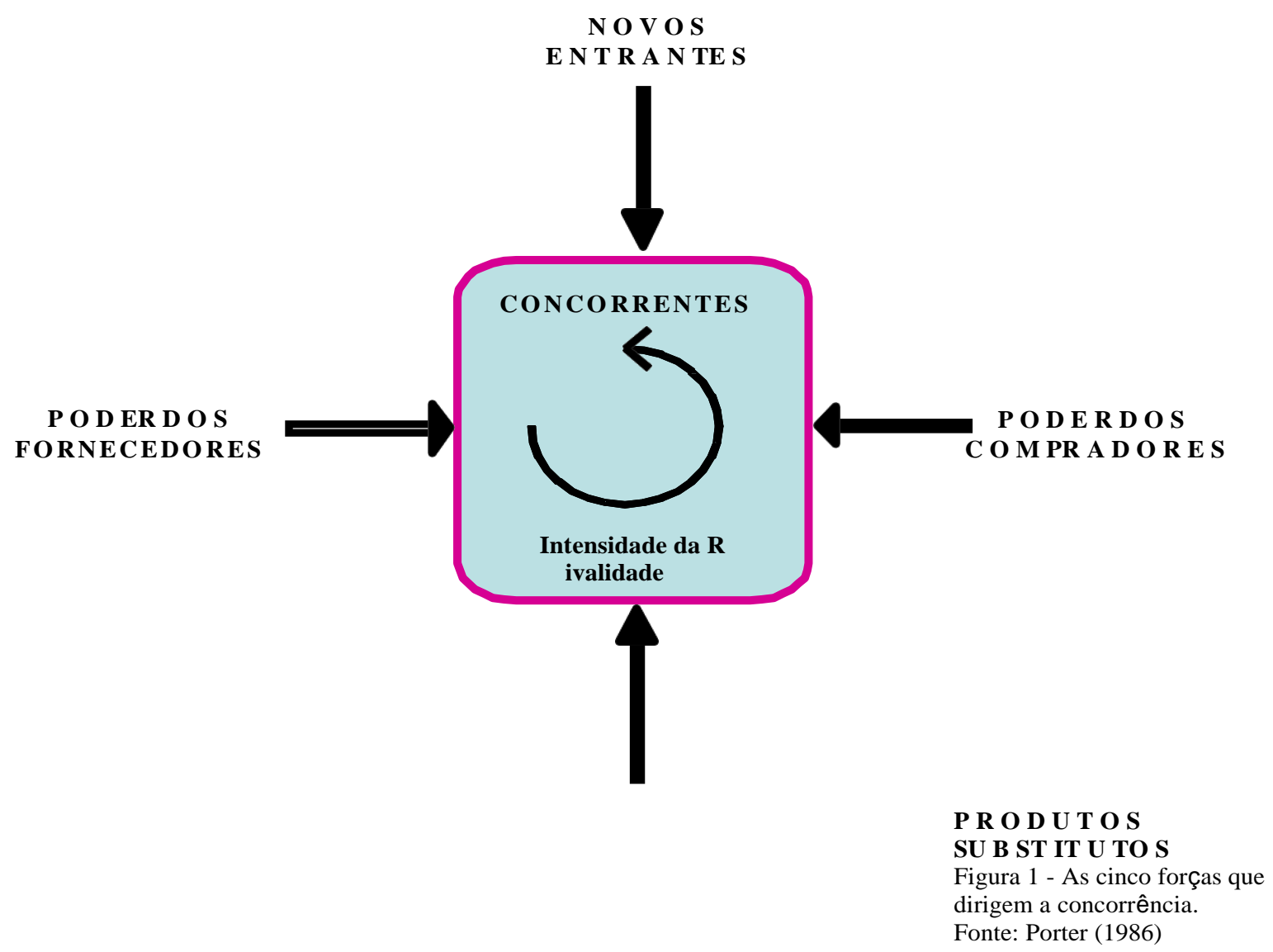


Reflexos das Mudanças na Concorrência do Setor da Aviação Comercial Brasileiro: Um Estudo no Âmbito da Desregulamentação Governamental e da Entrada da Companhia Gol Genossi Rauch Miotto, Marcos Antonio de Souza, Carlos Alberto Diehl

\subsubsection{Rivalidade entre os Concorrentes Existentes}

A rivalidade num setor assume a forma de disputa por lideranças com o uso de táticas como: disputas de preços; propaganda e publicidade; introdução de novos produtos; aumento dos serviços ou garantias ao cliente; dentre outros (Porter, 1986).

Essa rivalidade, de acordo com o autor, existe porque os concorrentes se sentem pressionados, ou porque identificam oportunidades para melhorar sua posição. As estratégias adotadas por uma empresa têm efeito nas outras e vice-versa. As guerras de preços podem desestabilizar um setor e, consequentemente, a empresa.

Por outro lado, deve-se reconhecer que guerras de publicidade podem difundir os produtos, elevando o consumo e a própria rentabilidade. Ou seja, independentemente dos benefícios individuais às empresas, o próprio setor como um todo é beneficiado.

A maior disputa de preços e rotas alternativas oferecidas pelas empresas após a flexibilização governamental tem sido uma realidade do setor aéreo comercial.

\subsubsection{Novos entrantes}

Os novos entrantes correspondem às empresas que trazem novos conceitos, com o objetivo de ganhar parcela de mercado e, frequentemente, oferecem recursos diferenciados. Como resultado de tais estratégias, os preços podem cair ou os custos dos participantes podem ser aumentados, reduzindo, assim, a rentabilidade (Porter, 1986).

Ainda segundo Porter (1986), a entrada de novos concorrentes depende das barreiras de entrada existentes; se forem rigorosas, a ameaça é reduzida, caso contrário é elevada. As barreiras podem referir-se à economia de escala, que faz com que os entrantes tenham que se instalar com uma escala mínima para equiparar seus custos. Gastos significativos com tecnologia, pesquisa e desenvolvimento e 
Reflexos das Mudanças na Concorrência do Setor da Aviação Comercial Brasileiro: Um Estudo no Âmbito da Desregulamentação Governamental e da Entrada da Companhia Gol Genossi Rauch Miotto, Marcos Antonio de Souza, Carlos Alberto Diehl

propaganda, também podem inibir os entrantes. A imagem das empresas atuais frente ao cliente também pode ser uma barreira de entrada.

Cabe aqui uma complementação aos exemplos citados pelo autor, que vão além das forças que emergem do mercado. Neste caso, a criação ou queda de barreiras é decorrente de maior ou menor liberalização que decorre de políticas estratégicas governamentais para mercados regulados e protegidos por legislação específica. É o caso do setor objeto deste estudo.

\subsubsection{Ameaça de substitutos}

Para Porter (1986), as empresas podem ter concorrentes em outro setor que produzam produtos ou serviços substitutos, ou seja, que possam desempenhar a mesma função. Como exemplo pode-se citar a popularização da Internet, que trouxe opções gratuitas em substituição aos serviços de telefonia. Uma pessoa conectada na rede pode comunicar-se on-line com outra pessoa em qualquer parte do mundo, pagando apenas pela tarifa de utilização da Internet. A utilização da Internet pode substituir também os serviços de correios e de fax, por meio dos e-mails.

No caso do setor de transporte aéreo comercial doméstico, alternativas do segmento de transporte (rodoviário, ferroviário, náutico) devem ser analisadas sob a ótica do usuário, em termos de maiores ou menores vantagens comparativas.

\subsubsection{Poder de negociação dos compradores}

Os clientes influenciam a concorrência no setor com seu poder de barganha, provocando a diminuição dos preços, jogando os concorrentes uns contra os outros. Nesta ótica, a seleção de clientes, ou seja, do mercado onde a empresa vai atuar, é uma decisão estratégica importante. Deve-se analisar o perfil dos clientes a fim de elaborar as políticas de atuação da em presa em busca dos melhores resultados econômicos (Porter, 1986).

Os compradores têm mais poder de negociação frente à empresa, caso o 
Reflexos das Mudanças na Concorrência do Setor da Aviação Comercial Brasileiro: Um Estudo no Âmbito da Desregulamentação Governamental e da Entrada da Companhia Gol Genossi Rauch Miotto, Marcos Antonio de Souza, Carlos Alberto Diehl

mercado onde ela atua tenha uma diversidade de concorrentes. A liberalização gradual do controle oficial de tarifas do setor aéreo incrementou a concorrência quanto a este aspecto.

\subsubsection{Poder de negociação dos fornecedores}

Para Porter (1986), um grupo de fornecedores é poderoso quando possui monopólio, produto diferenciado ou não concorre com produtos substitutos. Esse é o caso, por exemplo, dos aços planos e do cimento no Brasil, onde o grupo comprador é mais numeroso e tem poucas opções.

No caso do setor aéreo esta é uma questão especial. De fato, os três principais fornecedores do setor, dadas as suas características, limitam em muito a ação das companhias aéreas compradoras: (1) a infraestrutura aeroportuária, de natureza estatal; (2) os fornecedores de naves, assistência técnica e peças de manutenção que, além das poucas limitações, após a aquisição acabam por criar uma dependência natural; (3) os fornecedores de combustível, também concentrados em uma estrutura oficial.

\subsection{Uma visão mais objetiva das Forças Competitivas}

Segundo Freitas (1996, p.125), “a metodologia das cinco forças permite que a empresa observe a complexidade e aponte os fatores críticos para a concorrência em seu setor de atuação, como também a identificação das possíveis inovações estratégicas".

Greenwald e Kahn (2006) reconhecem que a obra de Porter trouxe uma nova visão ao pensamento estratégico, e o direcionou ao caminho certo; porém, para eles, essa metodologia, na prática, é bastante complexa. Os autores argumentam que identificar os inúmeros fatores integrantes do complexo modelo das cinco forças competitivas e avaliar o modo como eles se relacionam, tem se mostrado uma tarefa 
Reflexos das Mudanças na Concorrência do Setor da Aviação Comercial Brasileiro: Um Estudo no Âmbito da Desregulamentação Governamental e da Entrada da Companhia Gol Genossi Rauch Miotto, Marcos Antonio de Souza, Carlos Alberto Diehl

árdua e muitas vezes frustrante. Trabalhar as cinco forças em conjunto é demasiadamente abrangente, pode demandar muito tempo de análise e não proporcionar um foco definido para a organização, prejudicando a tomada de decisões.

Assim, Greenwald e Kahn (2006) propõem uma abordagem simplificada e concentrada nos novos entrantes, que, acreditam eles, constituem uma força dominante e a mais importante dentre todas. Subjacentes a essa força estão as barreiras de entrada. No caso de existência de barreiras de entrada, isso dificulta a inserção de novas empresas no mercado ou a expansão dos concorrentes existentes, e nenhuma outra característica do panorama competitivo tem tanta influência no sucesso da empresa como a sua proteção frente à concorrência.

Entende-se como procedente a interpretação dada por Greenwald e Kahn (2006), sobre a importância da análise dos novos entrantes e das possíveis barreiras de entrada em um setor, mesmo considerando-se que as barreiras de entrada são cada vez mais escassas e temporárias em um mercado dinâmico e mais liberalizante como o atual.

No estudo em questão, a análise de barreiras e novos entrantes tem um destaque especial dado que elas foram estabelecidas e flexibilizadas por influência de uma política governamental e não propriamente por iniciativa independente de novos entrantes.

\subsection{Transformações Ambientais do Setor de Aviação Comercial}

As transformações na aviação comercial brasileira durante a década de 1990 e suas consequências para todo setor esteve inserida em um movimento global nesse direcionamento, cuja base foi a reestruturação da aviação comercial mundial que iniciou com o processo de desregulamentação do transporte aéreo a partir de 1978 nos Estados Unidos.

Jesus (2005) destaca que a desregulamentação teve como objetivo abrir o mercado e incentivar a concorrência, mas teve como consequência uma onda de privatizações, 
Reflexos das Mudanças na Concorrência do Setor da Aviação Comercial Brasileiro: Um Estudo no Âmbito da Desregulamentação Governamental e da Entrada da Companhia Gol Genossi Rauch Miotto, Marcos Antonio de Souza, Carlos Alberto Diehl

fusões, aquisições e alianças entre as companhias aéreas, que levaram a uma grande concentração no mercado internacional. Como parte desta reestruturação, destaca-se a reorganização dos serviços das companhias e as inovações introduzidas nos equipamentos.

No Brasil, ainda conforme Jesus (2005), o processo de flexibilização da regulamentação começa no início dos anos 1990. A política de competição controlada, que se caracteriza por uma forte intervenção estatal no controle de rotas e tarifas, vigente desde os anos 1960, é gradativamente abandonada. Ao longo dos anos 1990 assiste-se à abertura do mercado e ao abandono do controle tarifário. Como consequência, observa-se um intenso movimento de entrada e saída de companhias aéreas no mercado resultando na concentração do setor. No período estudado por Jesus, de 1990 a 2002, ocorreu uma grande elevação das atividades do setor concomitante à redução do emprego, dos salários e do tempo de serviço, indicando uma maior instabilidade no mercado de trabalho da aviação comercial brasileira. Observa-se, ainda, uma significativa redução de custos com pessoal por parte das companhias.

Oliveira (2006) ao discorrer sobre as transformações ocorridas no setor de aviação comercial brasileiro, destaca duas grandes reformas regulatórias. A primeira iniciou no final dos anos 1960, consolidou-se na década de 1970 e extinguiu-se em 1992. Esta fase ficou conhecida como o período de competição controlada, com a autorização circunscrita a cinco companhias regionais e quatro com atuação nacional (Varig, Vasp, Cruzeiro do Sul e Transbrasil). A segunda foi introduzida no início da década de 1990 e que resultou na quase total desregulamentação do mercado. No final dos anos de 1990 as autoridades decidiram remover dois importantes dispositivos de controle da competição que ainda perduravam no setor, ou seja, as bandas tarifárias e a exclusividade do direito de as companhias regionais operarem linhas aéreas especiais. 

Âmbito da Desregulamentação Governamental e da Entrada da Companhia Gol Genossi Rauch Miotto, Marcos Antonio de Souza, Carlos Alberto Diehl

Como fase mais recente da desregulamentação, tem-se que a flexibilização estimulou a concorrência ao permitir, entre outras coisas, a entrada de novas empresas no mercado, a competição entre companhias aéreas regionais e nacionais e a extinção dos preços de referência. Essas medidas possibilitaram, por exemplo, a entrada da Tam - que nasceu como empresa aérea regional - em rotas nacionais e, mais tarde, a entrada de empresas como Gol e Bra, que se baseiam no modelo de baixo custo. Por outro lado, dificultaram as operações das empresas que antes detinham reserva de mercado, como Varig, Vasp e Transbrasil.

O Quadro 1, apresentado a seguir, expõe os principais pontos da evolução regulatória nas últimas décadas. 
Reflexos das Mudanças na Concorrência do Setor da Aviação Comercial Brasileiro: Um Estudo no Âmbito da Desregulamentação Governamental e da Entrada da Companhia Gol

Genossi Rauch Miotto, Marcos Antonio de Souza, Carlos Alberto Diehl

\begin{tabular}{|c|c|}
\hline Períodos & Evento \\
\hline 1973-1986 & $\begin{array}{l}\text { 1. Preços fixados pelo DAC e controle sobre o aumento das tarifas; } \\
\text { 2. Limite de quatro companhias aéreas nacionais e cinco regionais (monopólios } \\
\text { regionais); } \\
\begin{array}{r}\text { 3. Entrada de novas companhias não permitida e desestímulo à concorrência. }\end{array}\end{array}$ \\
\hline 1986-1992 & $\begin{array}{l}\text { 1. Congelamento de preços das passagens, como parte dos planos de controle } \\
\text { de inflação; } \\
\text { 2. Imposição de limites das tarifas; } \\
\text { 3. Entrada de novas companhias não permitida e desestímulo à concorrência. }\end{array}$ \\
\hline $1992-1997$ & $\begin{array}{l}\text { 1. Fixação de preços é abolida; } \\
\text { 2. Limites sobre os preços são mantidos; } \\
\text { 3. Monopólios regionais são abolidos; } \\
\text { 4. Entrada de novas companhias é permitida e estimulada. }\end{array}$ \\
\hline $1998-2001$ & $\begin{array}{l}\text { 1. Limites sobre os preços são extintos; } \\
\text { 2. Competição entre as companhias é estimulada; } \\
\text { 3. Autoridades antitruste monitoram o mercado para evitar aumentos abusivos } \\
\text { nas tarifas. }\end{array}$ \\
\hline 2001-2002 & $\begin{array}{l}\text { 1. Controle sobre os preços são extintos por completo; } \\
\text { 2. Políticas econômicas voltadas para o setor são desfeitas; } \\
\text { 3. Período mais próximo da desregulamentação. }\end{array}$ \\
\hline A partir de 2003 & $\begin{array}{l}\text { 1. DAC emite portarias para evitar excesso de capacidade; } \\
\text { 2. Importação de novas aeronaves é proibida; } \\
\text { 3. Controle sobre os preços são impostos; } \\
\text { 4. Período de re-regulamentação; } \\
\text { 5. Criação da Agência Nacional da Aviação Civil - ANAC. }\end{array}$ \\
\hline
\end{tabular}

Quadro 1: Principais alterações regulatórias no setor de aviação comercial brasileiro. Fonte: Oliveira (2006).

Verifica-se que o setor de aviação comercial já foi protegido pelas barreiras de entrada governamentais, mas após a desregulamentação abriu-se para a livre concorrência. Diante disso, pode ser entendido focando-se a análise nos novos entrantes.

Em 2001, a Gol, empresa de maior crescimento no setor na época mais recente, iniciou suas atividades e inovou, em termos domésticos, ao adotar um novo modelo de negócios, intitulado internacionalmente low cost, low fare. Apresentou expressivo e rápido crescimento entre 2001 e 2006, além de provocar mudanças estruturais no setor. 
Reflexos das Mudanças na Concorrência do Setor da Aviação Comercial Brasileiro: Um Estudo no Âmbito da Desregulamentação Governamental e da Entrada da Companhia Gol Genossi Rauch Miotto, Marcos Antonio de Souza, Carlos Alberto Diehl

Essa estratégia adotada pela Gol já havia sido objeto de adoção por outras empresas no exterior. Wright, Krol e Parnell (2000) destacam a atuação da empresa americana Southwest Airlines que 30 anos antes que a Gol, em 1971, decidiu-se com pleno sucesso pelo mesmo caminho estratégico de preços baixos. Os autores destacam as diversas ações da empresa em configurar uma atuação com baixos custos, de modo a viabilizar economicamente a nova postura de mercado.

Além de todo esse processo de concorrência liberada, o expressivo crescimento e desempenho da Gol estimula a realização do presente artigo com o objetivo de analisar as mudanças causadas pela concorrência do setor de aviação comercial brasileiro em âmbito doméstico a partir dessa nova entrante no mercado. O foco está em apontar as ações, reações e novos posicionamentos no ambiente concorrencial.

\section{ASPECTOS METODOLÓGICOS}

Dada a sua natureza e objetivo, a presente pesquisa é classificada como descritiva. Para Cervo e Bervian (2002, p. 66), a pesquisa descritiva "[...] observa, registra, analisa e correlaciona fatos ou fenômenos sem manipulá-los". Ainda, segundo Cervo e Bervian (2002, p. 66), esse tipo de pesquisa permite "descobrir, com a precisão possível, a frequência com que um fenômeno ocorre, sua relação e conexão com outros, sua natureza e características".

Esta pesquisa também tem natureza explicativa. Segundo Gil (2002 p. 42), "algumas pesquisas descritivas vão além da simples identificação da existência de relação entre variáveis, e pretende determinar a natureza dessa relação. Neste caso, tem-se uma pesquisa descritiva que se aproxima da explicativa".

Quanto à coleta de dados, a pesquisa é classificada como documental. Segundo Gil (2002), a pesquisa documental é realizada em documentos publicados e conservados em órgãos públicos e privados, de qualquer natureza. Em tal pesquisa os 
Reflexos das Mudanças na Concorrência do Setor da Aviação Comercial Brasileiro: Um Estudo no Âmbito da Desregulamentação Governamental e da Entrada da Companhia Gol Genossi Rauch Miotto, Marcos Antonio de Souza, Carlos Alberto Diehl

dados coletados precisam passar por um tratamento especial visando adaptá-los à finalidade e objetivo do estudo. A principal base de dados utilizada compreende os Anuários de Transporte Aéreo publicados pela Agência Nacional de Aviação Civil ANAC.

O tratamento e análise dos dados caracterizam a utilização de dados quantitativos para uma análise qualitativa. Trata-se, portanto, de uma pesquisa do tipo quali-quanti, tendo em vista os aspectos qualitativos e quantitativos envolvidos no seu desenvolvimento (Malhotra, 2000).

\section{APRESENTAÇÃO E ANÁLISE DOS DADOS}

A partir das medidas de desregulamentação do transporte aéreo brasileiro, conforme abordado anteriormente, ocorreu um expressivo incremento no nível da concorrência no setor. As principais empresas estabelecidas na época perderam a proteção governamental contra novos entrantes.

Em agosto de 2000, o então Departamento de Aviação Civil - DAC (substituído pela Agência Nacional de Aviação Civil - ANAC - a partir 2005), autorizou as operações da Gol Linhas

Aéreas Inteligentes como uma companhia aérea regular, tratada com as mesmas regras que as demais companhias. Em 2001, a Gol iniciou suas atividades. A companhia foi estruturada com a adoção de um modelo de negócios internacionalmente intitulado como low cost, low fare (baixo custo, baixa tarifa). A empresa apresentou expressivo e rápido crescimento no período de 2001 a 2006. 
Reflexos das Mudanças na Concorrência do Setor da Aviação Comercial Brasileiro: Um Estudo no Âmbito da Desregulamentação Governamental e da Entrada da Companhia Gol Genossi Rauch Miotto, Marcos Antonio de Souza, Carlos Alberto Diehl

Tabela 1: Percentual de participação das companhias na demanda

\begin{tabular}{|c|c|c|c|c|c|c|c|}
\hline & Gol & Ta & Trans & Vari & Vas & Outra & Total \\
\hline 1997 & na & 16 & 18 & 40 & 18 & 8 & 100 \\
\hline 1998 & na & 20 & 16 & 37 & 19 & 9 & 101 \\
\hline 1999 & na & 24 & 16 & 34 & 16 & 10 & 100 \\
\hline 2000 & na & 27 & 12 & 31 & 15 & 15 & 100 \\
\hline 2001 & 5 & 31 & 7 & 29 & 15 & 19 & 106 \\
\hline 2002 & 12 & 35 & na & 27 & 13 & 14 & 101 \\
\hline 2003 & 19 & 33 & na & 30 & 12 & 5 & 99 \\
\hline 2004 & 22 & 36 & na & 30 & 9 & 3 & 100 \\
\hline 2005 & 27 & 43 & na & 26 & na & 5 & 100 \\
\hline 2006 & 34 & 50 & na & 10 & na & 5 & 100 \\
\hline
\end{tabular}

Fonte: Adaptado dos Anuários da ANAC (2007), nos períodos analisados

A Tabela 1 apresenta um histórico do percentual de participação das principais companhias na demanda do setor. As participações das companhias de menor porte foram consolidadas e adicionadas na tabela sob a denominação "Outras".

Nos dados da Tabela 1 constata-se que em 1997 a Varig detinha $40 \%$ da demanda do mercado doméstico de aviação, e que a mesma foi perdendo participação, enquanto a concorrente Tam aumentava significativamente a sua participação. Essa evolução da Tam é reflexo do término da política de competição controlada, vigente até os anos 1990. Foi quando a Tam passou de uma atuação regional para uma companhia de âmbito nacional. Além disso, observa-se também que a Tिransbrasil encerrou as atividades em 2001, enquanto que a Vasp apresentou queda constante da participação, até encerrar as atividades em 2004.

Com os dados da Tabela 1 ainda é possível verificar que entre 1997 e 2002 também ocorreu um aumento na participação das companhias de menor porte que, assim como a Tam, absorveram parte dos passageiros da Transbrasil, da Varig e da Vasp. Porém, a partir de 2001 uma nova companhia entrou no mercado, a Gol, demonstrando um rápido crescimento, absorvendo grande parte dos passageiros atendidos pelas outras empresas já estabelecidas.

A Varig, líder de mercado por décadas, perdeu a liderança para a Tam no ano 
Reflexos das Mudanças na Concorrência do Setor da Aviação Comercial Brasileiro: Um Estudo no Âmbito da Desregulamentação Governamental e da Entrada da Companhia Gol Genossi Rauch Miotto, Marcos Antonio de Souza, Carlos Alberto Diehl

de 2001 e foi ultrapassada pela Gol em 2005.

Para obter tal crescimento, a Gol entrou no mercado adotando estratégias agressivas, destacando-se as promoções revolucionárias de venda de passagens por $R \$ 50,00$. A estratégia servia para lotar os vôos e, ainda, divulgar a imagem da empresa como uma companhia de "baixa tarifa". Ao longo do tempo, a estratégia de promoções também passou, mesmo que parcialmente, a ser utilizada pelas empresas concorrentes.

Um dos principais reflexos do novo entrante, a Gol, foi a popularização do transporte aéreo, pois a empresa estabeleceu em seus primeiros anos de atuação uma tarifa média muito abaixo das cobradas pelos concorrentes conquistando, assim, uma parcela significativa do mercado. No Gráfico 1 demonstra-se a evolução das tarifas médias por passageiro/km/transportado das principais companhias assim como da média do setor.

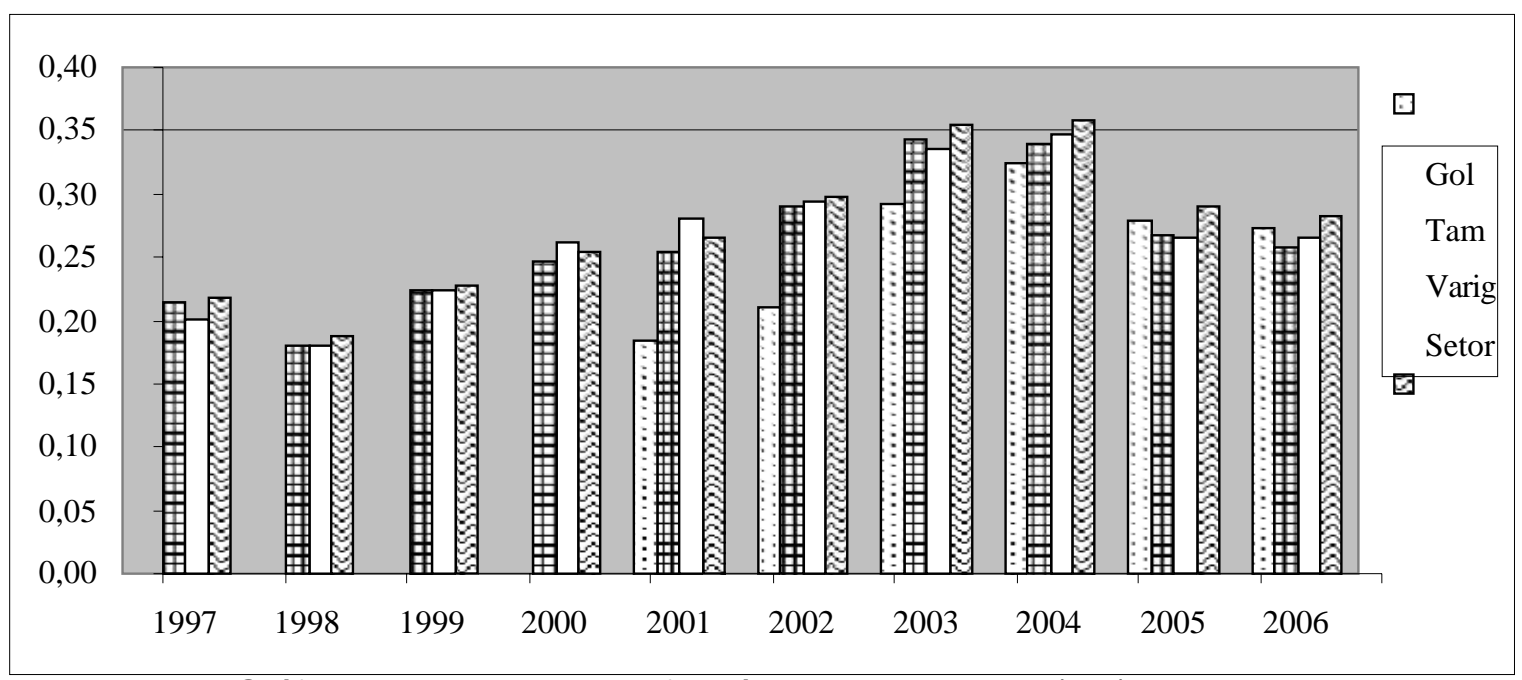

Gráfico 1: Evolução da tarifa média por passageiro $/ \mathrm{km} /$ transportado Fonte: Anuários da ANAC (2007), nos períodos analisados.

O Gráfico 1 apresenta uma mudança no cenário com relação as tarifas praticadas a partir da entrada da companhia Gol. Ela entrou no setor com uma tarifa 
Reflexos das Mudanças na Concorrência do Setor da Aviação Comercial Brasileiro: Um Estudo no Âmbito da Desregulamentação Governamental e da Entrada da Companhia Gol Genossi Rauch Miotto, Marcos Antonio de Souza, Carlos Alberto Diehl

abaixo das concorrentes e ao longo do tempo aumentou a sua tarifa média, enquanto as demais companhias diminuíram seus preços. A relativa redução das tarifas das demais companhias pode ser observada a partir do ano de 2005. Verifica-se que em 2005 e 2006 a Gol praticou tarifa média por passageiro/km. transportado, mais alta que suas principais concorrentes, Tam e Varig.

Analisada isoladamente, a redução das tarifas médias pode impactar diretamente no resultado operacional das companhias, diminuindo-o. Para que isto não ocorra, as companhias precisam trabalhar dois fatores fundamentais: a possível redução dos custos fixos (estruturais), e a melhoria do aproveitamento das aeronaves. Isso pode ser observado nas próximas tabelas.

No setor de aviação os custos podem ter a seguinte classificação: (1) custos variáveis em relação à realização do voo e fixos em relação ao aproveitamento das aeronaves; (2) custos variáveis, e (3) custos fixos. Explica-se a seguir o entendimento dado a essas categorias de custos.

Custos variáveis em relação a realização do voo e fixos em relação ao aproveitamento das aeronaves: no setor de aviação alguns custos ocorrem somente se o voo se realizar; são, desta forma, variáveis em relação ao voo. Porém, no momento em que 0 voo se realiza, tais custos transformam-se em fixos independentemente da taxa de ocupação da aeronave. São exemplos: taxa de pouso, combustível, auxílio à navegação e organização terrestre.

Custos variáveis: nessa classificação somente pode-se considerar os custos diretamente ligados à quantidade de passageiros, por exemplo, o serviço de bordo (alimentação) e comissões sobre venda de bilhetes.

Custos fixos: nesse grupo são classificados os demais custos, de natureza estrutural e que existem independentemente da ocorrência dos voos, por exemplo: os custos com pessoal.

Apresenta-se a seguir a simulação de algumas possíveis situações operacionais 
Reflexos das Mudanças na Concorrência do Setor da Aviação Comercial Brasileiro: Um Estudo no Âmbito da Desregulamentação Governamental e da Entrada da Companhia Gol

Genossi Rauch Miotto, Marcos Antonio de Souza, Carlos Alberto Diehl

para ilustrar as citadas classificações de custos e facilitar o entendimento dos seus possíveis impactos no resultado das empresas.

Supõe-se que uma aeronave tenha 130 assentos disponíveis e que o preço médio da passagem para um trajeto pré-definido seja de $R \$ 200,00$. Tem-se, ainda, os seguintes dados: (1) custo com alimentação e outros confortos a passageiros na faixa de $R \$ 20,00$ por passageiro; (2) custo com combustível de $R \$ 3.800,00$ para o trajeto; (3) taxas de pousos no total de $R \$ 200,00$; (4) auxílio à navegação no valor de $R \$$ 300,00; (5) organização terrestre de $R \$ 150,00$. A questão é: como ficaria a distribuição dos custos e a margem de contribuição considerando-se as opções de não realização do voo e realização do voo com diferentes taxas de aproveitamento da aeronave (70\%, $80 \%$ e $90 \%) ?$

Tabela 2 - Impacto do aproveitamento da aeronave nos custos variáveis e na margem de contribuição*

\begin{tabular}{|c|c|c|c|c|}
\hline \multicolumn{5}{|c|}{ Aproveitamento } \\
\hline Item & $\begin{array}{c}\text { Não realização } \\
\text { do vôo }\end{array}$ & $\begin{array}{c}\text { Aprov. } \\
\mathbf{7 0 \%}\end{array}$ & $\begin{array}{c}\text { Aprov. } \\
\mathbf{8 0 \%}\end{array}$ & Aprov. 90\% \\
\hline Faturamento & 0 & 18200 & 20800 & 23400 \\
\hline Serviço ao passageiro & 0 & -1820 & -2080 & -2340 \\
\hline Taxas de pouso & 0 & -200 & -200 & -200 \\
\hline Combustível & 0 & -3800 & -3800 & -3800 \\
\hline Auxílio à navegação & 0 & -300 & -300 & -300 \\
\hline Organização terrestre & 0 & -150 & -150 & -150 \\
\hline Contribuição marginal & 0 & 11930 & 14270 & 16610 \\
\hline Margem de & 0 & $66 \%$ & $69 \%$ & $71 \%$ \\
\hline Contribuição & & &
\end{tabular}

* Conforme Martins (2003), margem de contribuição é a diferença entre o preço de venda e os custos e despesas variáveis; é o valor que sobra entre a receita e os custos e despesas relacionados à existência da receita.

Fonte: Elaborado pelos autores

Os dados da Tabela 2 evidenciam que se o voo não se realizar não ocorrerá a 
Reflexos das Mudanças na Concorrência do Setor da Aviação Comercial Brasileiro: Um Estudo no Âmbito da Desregulamentação Governamental e da Entrada da Companhia Gol Genossi Rauch Miotto, Marcos Antonio de Souza, Carlos Alberto Diehl

receita e também nenhum dos custos citados, demonstrando que eles são variáveis em relação à realização do voo. Porém, uma vez ocorrendo voo, todos os custos, exceto o de serviço ao passageiro, tornam-se fixos. Por outro lado, constata-se que a receita é variável de acordo com o aproveitamento da aeronave, o que impacta diretamente na margem de contribuição do voo.

Portanto, o aproveitamento das aeronaves, dado que boa parte dos custos se tornam fixos, é decisivo no resultado das operações. Por isso, além da tarifa média (Gráfico 1) e da taxa de ocupação das aeronaves (Tabela 3), faz-se mister conhecer a evolução da ocupação no setor e nas companhias.

Assim, para completar essa análise, tem-se na Tabela 3 os dados referentes ao histórico do aproveitamento das aeronaves pelas principais companhias e do setor, para o período de 1997 e 2006. O aproveitamento foi obtido pela relação entre os indicadores passageiro $/ \mathrm{km}$. transportado e assentos $/ \mathrm{km}$. oferecidos.

Tabela 3: Percentual de aproveitamento das aeronaves

\begin{tabular}{|c|c|c|c|c|c|c|c|c|c|c|}
\hline \multicolumn{10}{|c|}{ Ano } \\
\hline Empresa & $\mathbf{1 9 9 7}$ & $\mathbf{1 9 9 8}$ & $\mathbf{1 9 9 9}$ & $\mathbf{2 0 0 0}$ & $\mathbf{2 0 0 1}$ & $\mathbf{2 0 0 2}$ & $\mathbf{2 0 0 3}$ & $\mathbf{2 0 0 4}$ & $\mathbf{2 0 0 5}$ & $\mathbf{2 0 0 6}$ \\
\hline Gol & na & na & na & na & 60 & 63 & 65 & 68 & 74 & 75 \\
\hline Tam & 48 & 56 & 49 & 55 & 55 & 53 & 58 & 64 & 71 & 74 \\
\hline Varig & 64 & 61 & 64 & 67 & 62 & 61 & 63 & 67 & 71 & 63 \\
\hline Setor & 58 & 59 & 55 & 59 & 58 & 57 & 60 & 65 & 71 & 72 \\
\hline
\end{tabular}

Fonte: Adaptado dos Anuários da ANAC (2007), nos períodos analisados

Observa-se pelos dados da Tabela 3 que a empresa Gol, já em seu primeiro ano e atuação, obteve um percentual de aproveitamento de $60 \%$ maior que o do setor (58\%) e inferior ao da Varig (62\%). A partir de 2001 o aproveitamento das aeronaves das empresas em geral melhorou significativamente, com destaque para a Gol que ao longo do período mantém o melhor aproveitamento; também deve ser destacado o caso da Tam, que evoluiu de 48\% em 1997 para 74\% em 2006. 
Reflexos das Mudanças na Concorrência do Setor da Aviação Comercial Brasileiro: Um Estudo no Âmbito da Desregulamentação Governamental e da Entrada da Companhia Gol Genossi Rauch Miotto, Marcos Antonio de Souza, Carlos Alberto Diehl

É necessário ressaltar que $\mathrm{O}$ aproveitamento das aeronaves depende basicamente de dois fatores: gestão dos recursos da empresa (aspecto interno) e demanda de passageiros (aspecto externo). Em termos de melhor gestão dos recursos internos, a empresa pode ter tanto recursos mais adaptados às necessidades da competição como maior eficiência operacional.

Do ponto de vista das características dos recursos, é importante entender, no setor de aviação civil, que o principal deles corresponde às características físicas das aeronaves. A adequação das aeronaves é determinante para a ocupação e, portanto, para o resultado operacional. Nesse sentido, a Tam reestruturou sua frota de aeronaves, substituiu seus aviões menores (Fokker 100) por novos e de maior porte Airbus (Miotto; Souza; Diehl, 2007). Prova disto é que em 1997 a empresa havia oferecido cerca de 5 bilhões de assentos. km e em 2005 aumentou para 21 bilhões, consequência do aumento do número de voos e pela maior capacidade das aeronaves (ANAC, 2006). A Tam apresentava em 1997 aeronaves com número médio de assentos abaixo das outras companhias. Essa estratégia era consistente com o foco em rotas regionais, área de atuação original de atuação da empresa na época da concorrência controlada. A partir da expansão em nível nacional e até internacional, os assentos médios por aeronave aumentaram de $68 \mathrm{em} 1997$ para $145 \mathrm{em} 2006$. Essa mudança, aliada as promoções nos preços das passagens, é uma das razões que explica um melhor aproveitamento das aeronaves.

Do ponto de vista da eficiência operacional, a identificação direta das práticas é mais difícil de fazer e complexa de comparar. Assim, como medida da eficiência operacional, os custos operacionais podem indicar qual das companhias esteve em vantagem. O Gráfico 2 mostra uma evolução dos gastos por passageiro/km. transportado, onde é importante destacar as mudanças ocorridas a partir da entrada da Gol em 2001. 


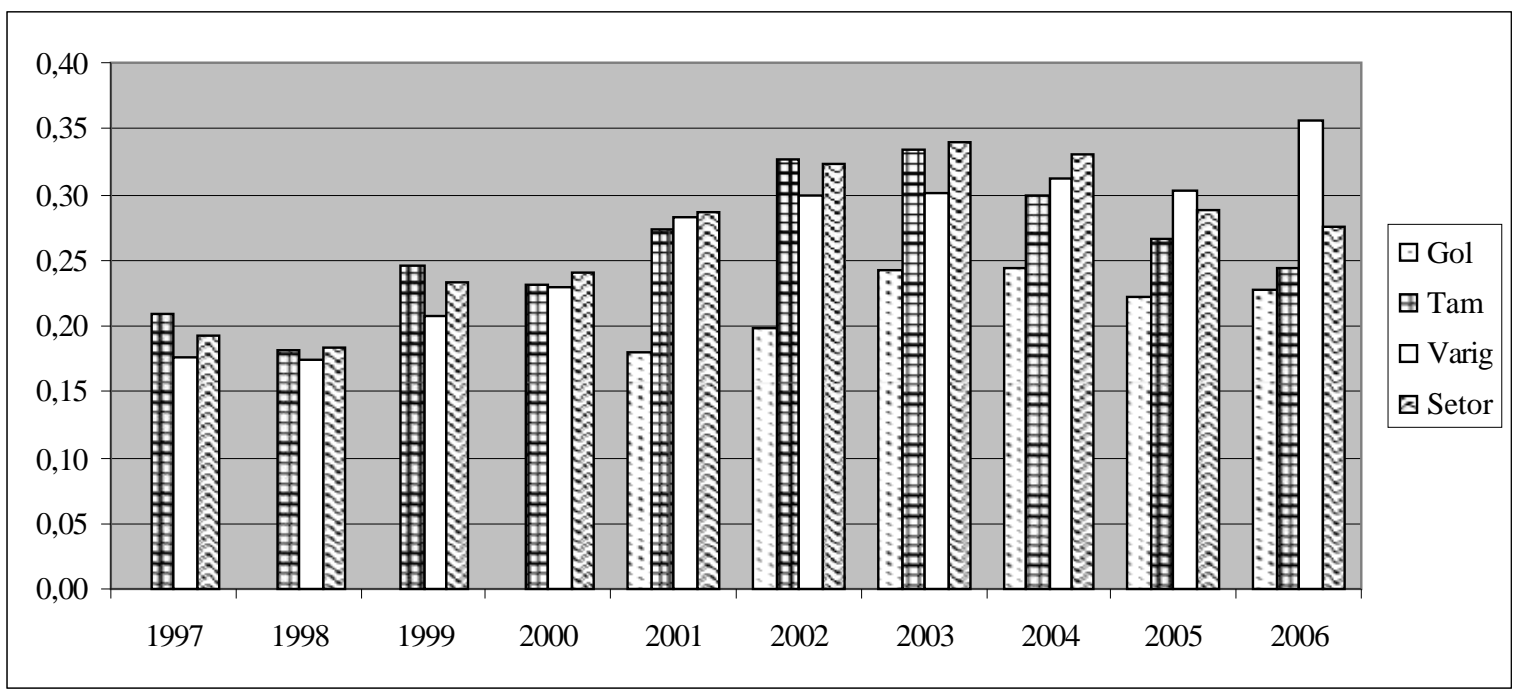

Gráfico 2: Evolução do gasto médio por passageiro/km. transportado por companhia e do setor Fonte: Anuários da ANAC (2007), nos períodos analisados

Em 2001 e 2002 os custos da Gol eram significativamente inferiores aos das empresas concorrentes. Porém, a partir de 2003 as demais companhias foram diminuindo tal diferença e equiparando-se aos gastos da entrante Gol, a qual apresentou ligeiro aumento ao longo do tempo. Verifica-se, também, que a companhia Tam obteve o maior êxito na diminuição dos seus custos.

Conforme tratado anteriormente, a Tam se reestruturou para buscar maior competitividade, atingindo a liderança de mercado em 2001. Uma das ações mais significativas foi a melhora significativa verificada no aproveitamento das suas aeronaves (Tabela 3), cujo impacto mais evidente surge na redução dos custos por passageiro/km. transportado (Gráfico 2). Contrariamente a esse desempenho observa-se a desfavorável posição da Varig.

Tanto a questão tarifária quanto o controle dos custos refletem diretamente no resultado econômico das companhias. A fim de analisar o comportamento do resultado das empresas, apresenta-se na Tabela 4 um comparativo do seu percentual de margem de lucro operacional ao longo do período analisado. 
Reflexos das Mudanças na Concorrência do Setor da Aviação Comercial Brasileiro: Um Estudo no Âmbito da Desregulamentação Governamental e da Entrada da Companhia Gol Genossi Rauch Miotto, Marcos Antonio de Souza, Carlos Alberto Diehl

Tabela 4: Percentual de Margem Operacional sobre a Receita

\begin{tabular}{|l|c|c|c|c|c|c|c|c|c|c|}
\hline Empresa & $\mathbf{1 9 9 7}$ & $\mathbf{1 9 9 8}$ & $\mathbf{1 9 9 9}$ & $\mathbf{2 0 0 0}$ & $\mathbf{2 0 0 1}$ & $\mathbf{2 0 0 2}$ & $\mathbf{2 0 0 3}$ & $\mathbf{2 0 0 4}$ & $\mathbf{2 0 0 5}$ & $\mathbf{2 0 0 6}$ \\
\hline Gol & $\mathrm{na}$ & $\mathrm{na}$ & $\mathrm{na}$ & $\mathrm{Na}$ & 2 & 6 & 17 & 24 & 20 & 16 \\
\hline Tam & 3 & -1 & -10 & 6 & -8 & -12 & 3 & 12 & 1 & 5 \\
\hline Varig & 12 & 3 & 8 & 12 & -1 & -2 & 11 & 11 & -12 & -33 \\
\hline Setor & 12 & 3 & -2 & 6 & -7 & -8 & 4 & 8 & 1 & 2 \\
\hline
\end{tabular}

Fonte: Adaptado dos Anuários da ANAC (2007), nos períodos analisados

O melhor resultado operacional observado é o da companhia Gol, que tem aumentado seu lucro em relação à receita ao longo do período $A$ Tam teve seus melhores resultados em 2003 e 2004. A Varig apresenta uma instabilidade nos resultados ao longo do período e uma relevante queda em 2005 e 2006. A Vasp apresentou uma sequência de resultados negativos, indo a falência em 2004.

No caso das empresas analisadas, verificou-se que a Gol, que entrou no mercado praticando menores tarifas, não apresentou margens inferiores às concorrentes. A Tam apresentou variação na margem líquida e períodos com margem negativa. Tal fato se deve a um momento de reestruturação da empresa, com recuperação em 2006. A Varig inicialmente demonstrou uma margem positiva, todavia, conforme o mercado se adaptava com novos entrantes e exigia a redução das tarifas, sua margem foi reduzida, principalmente, em 2005 e 2006. Nestes anos, quando reduziu significativamente a sua tarifa (Gráfico 1), a empresa apresentou com margens de $-12 \%$ e $-33 \%$, respectivamente (Tabela 4). Isso demonstra que a estrutura adotada pela Varig não era adequada para a convivência com as exigências ditadas pela nova configuração do mercado.

A demanda externa explica também a ocupação das aeronaves. Com maior número de passageiros transportados, é mais fácil fazer a alocação das aeronaves. Isso permite a melhor distribuição dos passageiros ao longo dos horários e rotas. Um número maior de passageiros também cria "filas", gerando um "estoque" de passageiros que permite mais facilmente a lotação dos voos mais procurados, elevando a taxa de ocupação média. A Tabela 5 mostra a evolução do número de 
Reflexos das Mudanças na Concorrência do Setor da Aviação Comercial Brasileiro: Um Estudo no Âmbito da Desregulamentação Governamental e da Entrada da Companhia Gol Genossi Rauch Miotto, Marcos Antonio de Souza, Carlos Alberto Diehl

passageiros/ km. transportados, de 2001 à 2005. Constata-se que a Gol e a Tam tiveram significativo aumento no número de passageiros $/ \mathrm{km}$. transportado, enquanto a Varig permaneceu com ligeiro aumento e a Vasp reduziu até encerrar as atividades. Como pode ser observado pelos dados da Tabela 3, esse comportamento coincide com a evolução da ocupação das aeronaves. Os dados da Tabela 5 ratificam tal constatação.

Tabela 5 - Passageiros/ Km Transportados (Milhões)

\begin{tabular}{|c|c|c|c|c|c|}
\hline Ano & $\mathbf{2 0 0 1}$ & $\mathbf{2 0 0 2}$ & $\mathbf{2 0 0 3}$ & $\mathbf{2 0 0 4}$ & $\mathbf{2 0 0 5}$ \\
\hline Gol & 1.261 & 3.224 & 4.817 & 6.034 & 9.392 \\
\hline Tam & 8.162 & 9.344 & 8.321 & 10.088 & 15.158 \\
\hline Varig & 7.614 & 7.133 & 7.586 & 8.376 & 9.169 \\
\hline Vasp & 3.804 & 3.386 & 3.072 & 2.440 & - \\
\hline SETOR & $\mathbf{2 6 . 2 9 6}$ & $\mathbf{2 6 . 7 8 4}$ & $\mathbf{2 5 . 0 9 3}$ & $\mathbf{2 7 . 8 9 3}$ & $\mathbf{3 5 . 3 5 1}$ \\
\hline Var \% & & $102 \%$ & $94 \%$ & $111 \%$ & $127 \%$ \\
\hline
\end{tabular}

Fonte: adaptado dos Anuários da ANAC (2007) nos períodos analisados

\section{CONCLUSÃO}

Ao longo deste artigo buscou-se analisar as mudanças na concorrência do setor de aviação comercial brasileiro em âmbito doméstico, principalmente, a partir da nova entrante, a companhia Gol. Para isso, a análise de dados deteve-se em seis variáveis principais: (1) participação de mercado; (2) tarifa média; (3) aproveitamento de aeronaves; (4) gasto médio por passageiro; (5) margem operacional; (6) quantidade de passageiros transportados, relacionadas às empresas e a partir da entrada da Gol.

Verificou-se que a entrante Gol, por meio do seu modelo de negócios de baixo custo e do objetivo de popularização do transporte aéreo, causou uma convergência no mercado de transporte aéreo doméstico para uma estratégia de liderança em custos. Segundo Beting (2006), ao longo dos anos a Gol utilizou eficientemente os recursos de 
Reflexos das Mudanças na Concorrência do Setor da Aviação Comercial Brasileiro: Um Estudo no Âmbito da Desregulamentação Governamental e da Entrada da Companhia Gol Genossi Rauch Miotto, Marcos Antonio de Souza, Carlos Alberto Diehl

marketing, destacando que a empresa convenceu a opinião pública de que voar economicamente era mais inteligente que voar sofisticadamente. Por meio de tarifas promocionais ela atraiu uma parcela da população que não utilizava o transporte aéreo devido ao conceito de sofisticação.

Os dados da pesquisa indicam que a companhia, inicialmente, atuou com tarifas baixas e margens reduzidas. Foi-se adequando ao mercado, e sua tarifa média em 2005 já não era menor que as concorrentes. Porém, busca manter seu conceito de baixa tarifa, através de estratégias de marketing, que unem promoções e divulgação.

Essa conclusão é ratificada por Gargioni (2007), para quem a Gol obteve sucesso ao mudar os paradigmas da aviação nacional, que trabalhava com a valorização de conceitos como sofisticação, requinte e glamour para a promoção do transporte aéreo. Os novos conceitos aplicados pela Gol são simplicidade, praticidade e eficiência.

As oscilações dos dados relativos às variáveis pesquisadas revelam que as empresas concorrentes buscaram se adequar à nova realidade de mercado. Dentre as principais companhias aéreas brasileiras que atuavam em âmbito doméstico em 2001, a única que obteve êxito na reestruturação e continua no mercado é a Tam.

As estratégias de adequação da Tam contemplaram, principalmente, a reestruturação da frota de aviões, substituindo os aviões Fokker 100 por novos Airbus, refletindo-se numa significativa redução nos custos com manutenção e combustível. Tratou-se de uma resposta à estratégia da nova entrante Gol, desde seu início operando com aeronaves mais modernas e eficientes.

Os resultados deste estudo corroboram a proposta de Porter (1986), de que novos entrantes podem causar transformações em um mercado, e que as empresas estabelecidas devem buscar compreender as necessidades dos clientes e adequar-se através de reavaliação das estratégias competitivas.

Para os gestores, fica evidenciada a importância de se reconhecer, com certa 
Reflexos das Mudanças na Concorrência do Setor da Aviação Comercial Brasileiro: Um Estudo no Âmbito da Desregulamentação Governamental e da Entrada da Companhia Gol

Genossi Rauch Miotto, Marcos Antonio de Souza, Carlos Alberto Diehl

antecipação, os movimentos competitivos em potencial, de novos entrantes, ainda mais quando essa entrada surge como inevitável. Preparar-se para reagir a esses movimentos pode ser decisivo para o sucesso, como mostrou a experiência da Tam ou para o fracasso, nos casos da Varig e da Vasp.

A compreensão dessa dinâmica pode ensejar novas pesquisas em outras áreas, com a mesma abordagem. Também pesquisas que aprofundem a forma como as empresas aéreas se moldaram a essa nova situação, pode explicar, do ponto de vista interno, as causas e os processos que levaram ou não a uma adaptação com sucesso. Acredita-se que um estudo de caso da gestão estratégica adotada pela principal concorrente, a Tam, para esse período de ingresso da entrante Gol, tem grande potencial de contribuir para o conhecimento da gestão empresarial.

\section{REFERÊNCIAS}

Agência Nacional de Aviação Civil - ANAC. (2007). Anuários de Transporte Aéreo 2001, 2002, 2003, 2004, 2005 e 2006. Disponível em: http://www.dac.gov.br. Acesso em: 03/nov/2007.

BETING, G. (2006). MAYDAY! Aviação brasileira em parafuso. Disponível em: http://www.jetsite.com.br. Acesso em: 25/jan/2007.

CERVO, A. L. e BERVIAN, P. A. (2002). Metodologia científica. São Paulo, Prentice Hall, $176 \mathrm{p}$.

FREITAS, H. G. T. (1996). Novos cenários da aviação brasileira: A gestão da empresa TAM, privilegiando a liderança, a qualidade de serviços, o marketing e a cultura organizacional. Salvador. (Dissertação de Mestrado). Universidade Federal da Bahia, Salvador, $156 \mathrm{p}$.

GIL, A. C. (2002). Como elaborar projetos de pesquisa. São Paulo, Atlas, 176 p.

GARGIONI, T. (2007). O Brasil faz um GOL no setor de aviação de baixo custo. Disponível em: http://www.wharton.universia.net. Acesso em: 23/março/2007.

GREENWALD, B. e KAHN, J. (2006). A estratégia competitiva desmistificada. Rio de 
Reflexos das Mudanças na Concorrência do Setor da Aviação Comercial Brasileiro: Um Estudo no Âmbito da Desregulamentação Governamental e da Entrada da Companhia Gol Genossi Rauch Miotto, Marcos Antonio de Souza, Carlos Alberto Diehl

Janeiro, Elsevier, 408 p.

HAMMER, M. (2001). A Agenda: o que as empresas devem fazer para dominar esta década. (3 ed.). Rio de Janeiro, Campus, 320 p.

HANSEN, D. R. e MOWEN, M. M. (2001). Gestão de custos: contabilidade e controle. São Paulo, Pioneira Thomson Learning, 783 p.

JESUS, C. G. (2005). Desregulamentação e trabalho na aviação comercial brasileira (1990-2002). Campinas, SP. (Dissertação de Mestrado). Universidade Estadual de Campinas - UNICAMP. Campinas, $99 \mathrm{p}$.

MALHOTRA, N. (2000). Pesquisa em marketing: uma orientação aplicada. Porto Alegre, Bookman, 720 p. MARTINS, E. 2003. Contabilidade de custos. (9 ed.). São Paulo, Atlas, 378 p.

MINTZBERG, H; AHLSTRAND, B e LAMPEL, J. (2000). Safári de estratégia: um roteiro pela selva do planejamento estratégico. Porto Alegre, Bookman, $304 \mathrm{p}$.

MIOTTO, G. R.; SOUZA M. A, e DIEHL, C. A. (2007). Análise da tecnologia como determinante de custos no setor de aviação comercial brasileiro. Anais...XIV Congresso Brasileiro de Gestão Estratégica de Custos. João Pessoa - PB.

MONTEIRO, C. F. (2007). Aviação comercial: globalização e a experiência brasileira. Revista Brasileira de Direito Aeroespacial. Rio de Janeiro. 79(2):7-25, disponível em http://www.sbda.org.br/revista/anterior/1688.htm. Acesso em 15/dezembro/2007.

MOSIMANN, C.P. e FISCH, S. (1999). Controladoria seu papel na administração de empresas. São Paulo, Atlas, 144 p.

NAKAGAWA, M. (2000). Gestão estratégica de custos: conceitos, sistemas e implementação: JIT/ TQC. São Paulo, Atlas, 112 p.

OLIVEIRA, A. V. M. (2007). A experiência brasileira na desregulamentação do transporte aéreo: um balanço e propositura de diretrizes para novas políticas. Brasília, 2006.

Disponível

em:

http://www.seae.fazenda.gov.br/central_documentos/documento_trabalho/copy_of_200 6/dt_45.pdf. Acesso em 09/dezembro/2007.

OTLEY, D. T. (1994). Management control in contemporary organizations: Towards a wider framework. Management Accounting Research, 5(3-4):289-299. 
Reflexos das Mudanças na Concorrência do Setor da Aviação Comercial Brasileiro: Um Estudo no Âmbito da Desregulamentação Governamental e da Entrada da Companhia Gol

Genossi Rauch Miotto, Marcos Antonio de Souza, Carlos Alberto Diehl

PORTER M. E. (1986). Estratégia competitiva: técnicas para análise de indústrias e da concorrência. Rio de Janeiro, Campus, 448 p.

PORTER M.E. (1989). Vantagem competitiva: criando e sustentando um desempenho superior. Rio de Janeiro, Campus, 536 p.

WRIGHT, P.; KROLL, M. J. e PARNELL, J. (2000). Administração estratégica. São Paulo, Atlas, $446 \mathrm{p}$.

Data de Submissão: 16/07/2008

Data de Aceite: 05/08/2008 